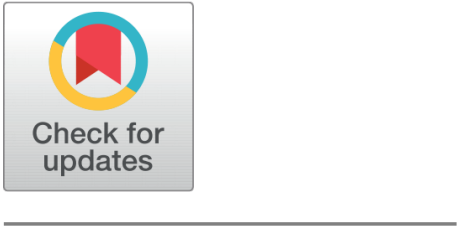

OPEN ACCESS

Received: 04.12.2019

Accepted: 31.12.2019

Published: 05.01.2020

Editor: Dr. D. R. Galfat

Citation: Hussain J, Pandey S, Shetty S, Dhond A (2020)

Morel-lavallee lesion - a Hidden degloving injury. International Journal of Orthopaedics Traumatology \& Surgical Sciences 6(1): 81-85. https://doi.org/ 10.47618/IJOTSS/v6i1.16

\section{*Corresponding author.} hussainjaved954@gmail.com

Funding: None

Competing Interests: None

Copyright: (c) 2020 Hussain et al. This is an open access article distributed under the terms of the Creative Commons Attribution License, which permits unrestricted use, distribution, and reproduction in any medium, provided the original author and source are credited.

Published By Society of Orthopaedics, Surgical and Dental Sciences

ISSN

Print: 2455-0809

Electronic: $2454-4167$

\title{
Morel-lavallee lesion - a Hidden degloving injury
}

\author{
Javed Hussain ${ }^{1}$, Shivam Pandey', Sunil Shetty ${ }^{2 *}$, Amit Dhond ${ }^{3}$ \\ 1 PG Resident, Dr. DY Patil hospital, Navi Mumbai \\ 2 HOU, Dr. DY Patil hospital, Navi Mumbai \\ 3 Associate Professor, Dr. DY Patil hospital, Navi Mumbai
}

\section{Abstract}

Morel-Lavallee lesion is a rare post traumatic soft tissue injury. It results in separation of the skin and subcutaneous tissue from the underlying fascia. An underlying blood filled cystic cavity is created. It is commonly causedby a shearing force resulting in separation of the hypodermis from the deeper fascia. It is most commonly seen around the greater trochanter. These injuries also occur at the flanks, buttocks, lumbar spine, scapula and the knee. Separation of the tissue planes result in a complex serosanguinous fluid collection with areas of fat within it. These lesions are usually missed during initial examination and become evident after few weeks or months. They may be associated with fractures. Magnetic resonance imaging is the modality of choice for the evaluation of this lesion. It plays a significant role in its diagnosis.

Keywords: Morel-Lavallee lesion; post traumatc injury; hidden injury

\section{Introduction}

Morel-Lavallee lesion, initially described by French surgeon Maurice MorelLavallee in 1853 , is a post- traumatic closed degloving injury where skin and superficial fascia get separated from deep fascia, creating a potential space. ${ }^{(1)}$ Injury to rich vascular and lymphatic supply leads to accumulation of blood and lymph in this potential space generated by separation of the superficial and deep fascia. Blood products and necrotic material in turn invokes chronic inflammatory reaction. As the time progress, a capsulated lesion lined by fibrous capsule develops, which is filled with blood products, necrotic fatty tissue, debris and fibrin. Morel- Lavallee lesions usually present as painful fluctuant swelling in the involved sites. Many of these may be missed at initial evaluation and present weeks to month after initial trauma. ${ }^{(2,3)}$

\section{Pathophysiology}

Though motor vehicle accidents are the most common etiology, low grade blunt force trauma including falls and sport related injuries account for a significant amount of cases. ${ }^{(3,4)}$ The greater trochanter is the most commonly involved region, accounting for over $60 \%$ of the cases. Predisposing factors include the superficial position of the femoral cortex, relative mobility of the subdermal soft tissues and strength of the underlying tensor fascia lata. Secondary risk factors include female gender and a body mass index of 25 or greater. With disruption of the subdermal capillaries and lymphatics, hemorrhage, lymphatic fluid and locules of subdermal fat pool in the 
suprafascial tissue plane. Over time, there is resorption of the haemorrhagic elements, increasing serosanguinous fluid and progressive fibrous encapsulation, hindering resorption and thus leading to slow continued expansion. ${ }^{(2,3,5)}$

\section{Case report}

A 26 year old female presented to our casualty with pain and abrasions over bilateral hip and upper thigh region along with pain \& deformity in the right thigh. Patient had a history of fall from train following which she was taken to a local hospital where she was stabilized and a skeletal traction was applied on the proximal tibia.

Patient presented to us after 3 days of accident. She was clinically stable on arrival. X-Ray $\mathrm{PBH}$ shows bilateral acetabulum with inferior and superior pubic rami and coccyx fracture. X-ray right femur shows mid-shaft fracture.

On $9^{\text {th }}$ day nailing for the shaft fracture femur (R) was done. On $5^{\text {th }}$ post operative day patient had serous discharge from the upper left thigh around the region of greater trochanter which continued for 3days. Hence on 11/06/19 wound was explored and debrided. On $10^{\text {th }}$ similar discharge was noticed on right thigh. On $17^{\text {th }}$ post operative day both thighs were explored and debrided. Dressings needed to be done twice daily. Inspite of all the care taken - the size of the subcutaneous cavity kept increasing. Exploration and debridement continued for a total of 15 debridments. Throughout the debridement fat necrosis was a notable feature. Throughout the procedure serous/pus was sent for $\mathrm{c} / \mathrm{s}$.Vac dressings were also done for both the wounds. Appropriate antibiotics were given whenever needed. It took a total of 5 months for the wounds to close.

Regular counseling and moral support is the most important need while dealing in these situations.

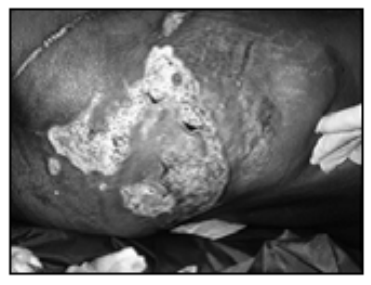

Fig 1. Wound over left hip

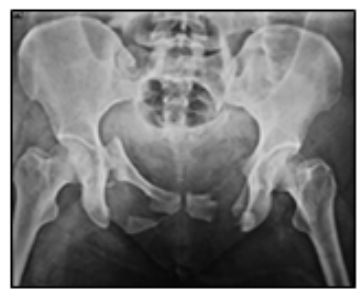

Fig 2. Xray PBH- bilateral acetabu- lum with superiorand inferior pubic rami with coccyx fracture

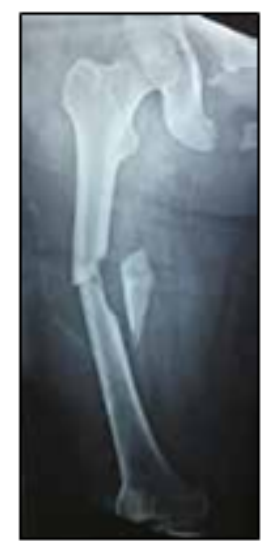

Fig 3. X ray femur showing mid shaft femur fracture

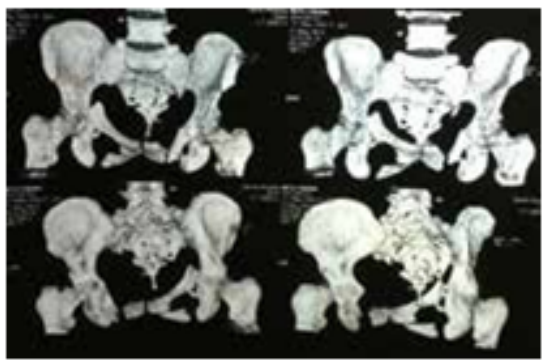

Fig 4. 3D CT Hip showing the bilateral acetabulum withsuperior and inferior rami fracture

\section{Management}

After the confirmation of diagnosis patient underwent a series of debridement (fifteen times in all) and the fracture femur was fixed with intramedullary nailing with distal locking only as the proximal screws couldn't be passed due to the location of the right abrasion and a proximal tibia skeletal traction was put on the right lower limb for stabilization of hip fracture.

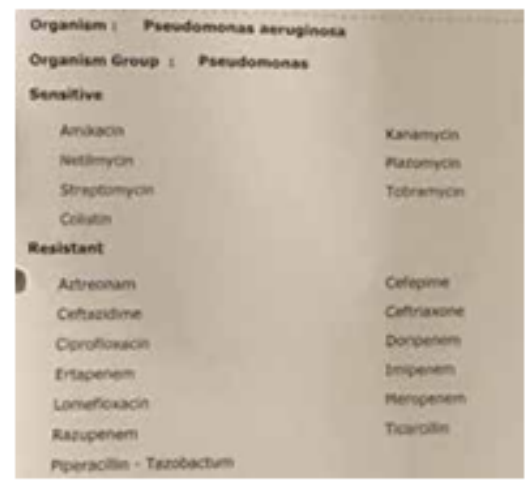

Fig 5. Superadded infections are common in these lesions 


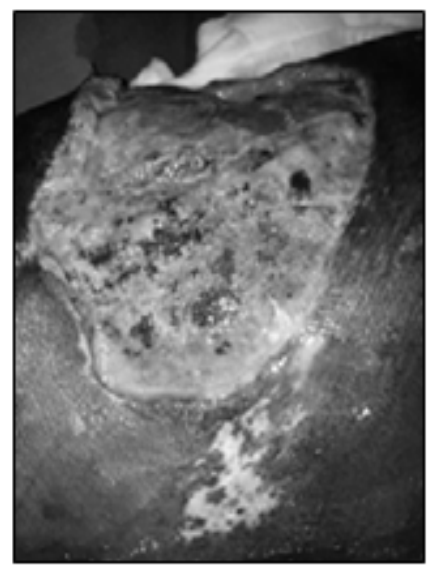

Fig 6. Wound showing Pseudomonas infection which was treated with iv antibiotics

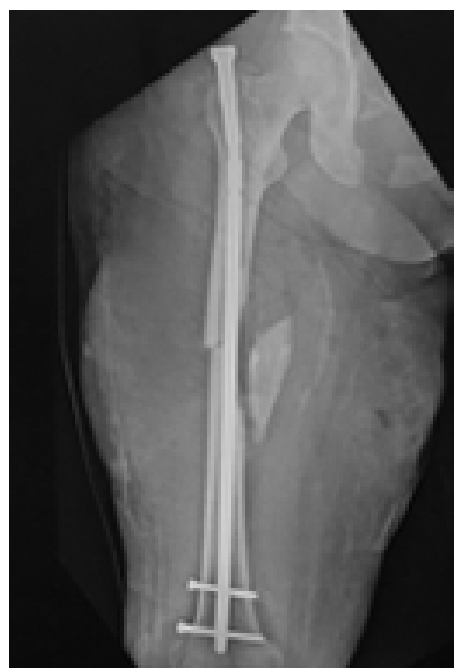

Fig 7. X ray right femur intra- medullary nail without proximal locking.

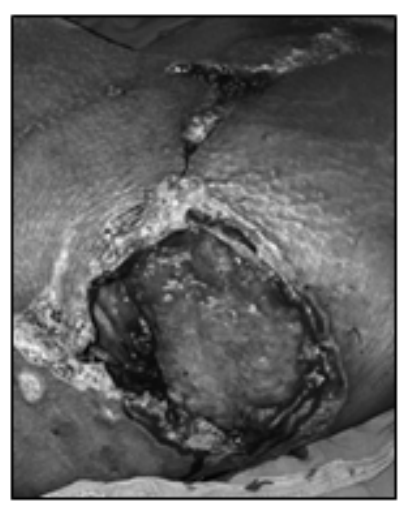

Fig 8. Wound of left hip after 1st debridement

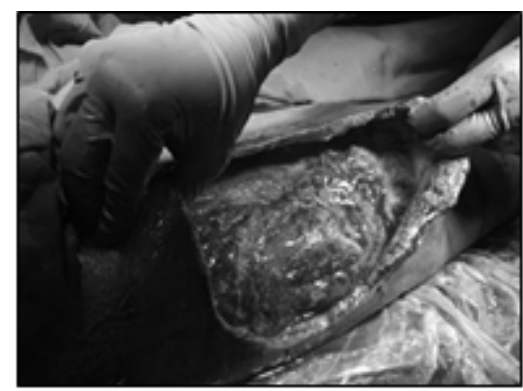

Fig 9. Wound right Hip after 1st debridement

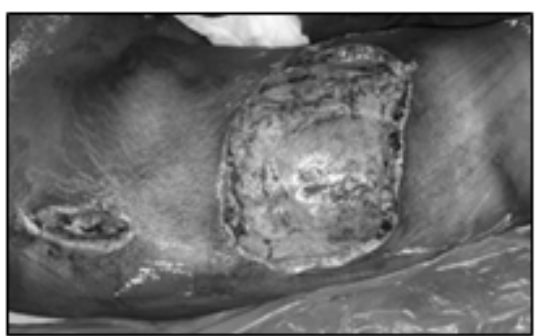

Fig 10. Wound right hip after 1 month of 1 s debridement and daily dressings

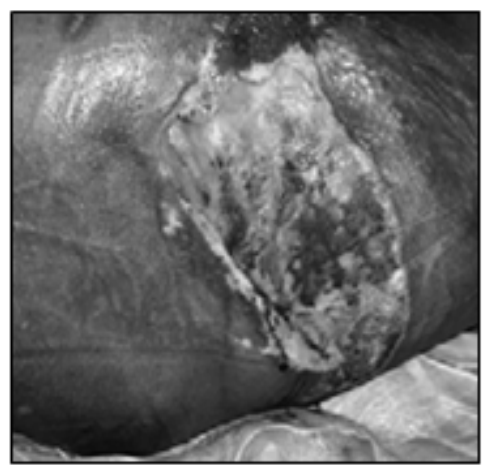

Fig 11. Wound left side after 1 month of daily dressings

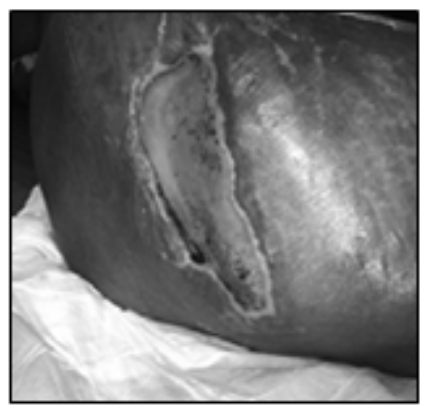

Fig 12. Wound left side after 2 month of dressings andvac 


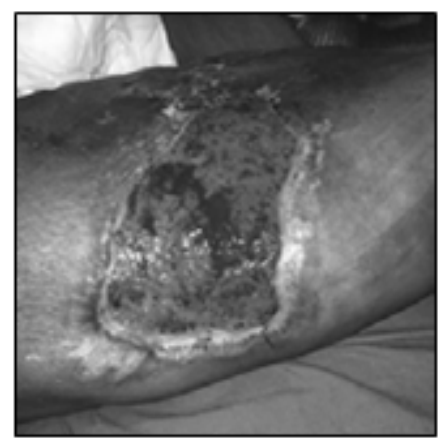

Fig 13. Wound right hip after 2 months of dressings and Vac application

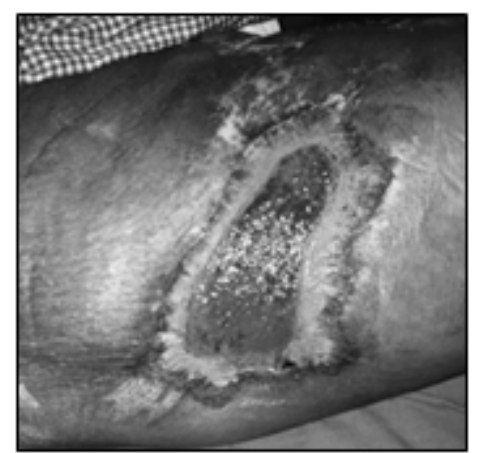

Fig 14. Wound right hip after 4 months

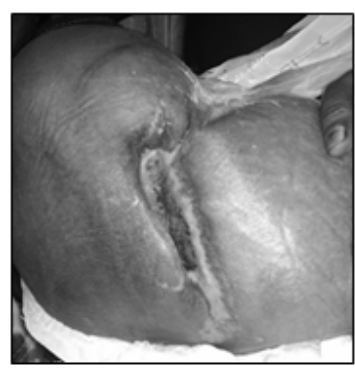

Fig 15. Wound left hip after 4 months

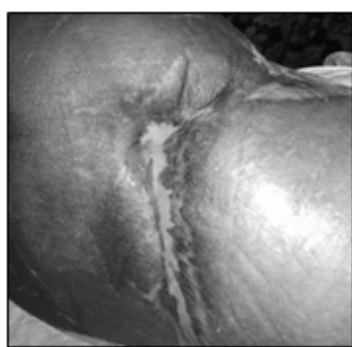

Fig 16. Wound left hip after 5 months

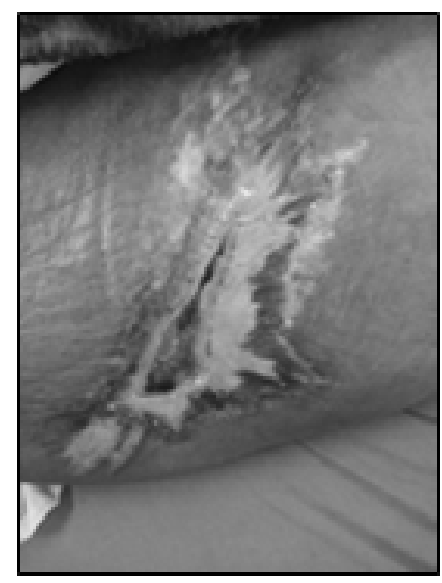

Fig 17. Wound right hip after 5 months

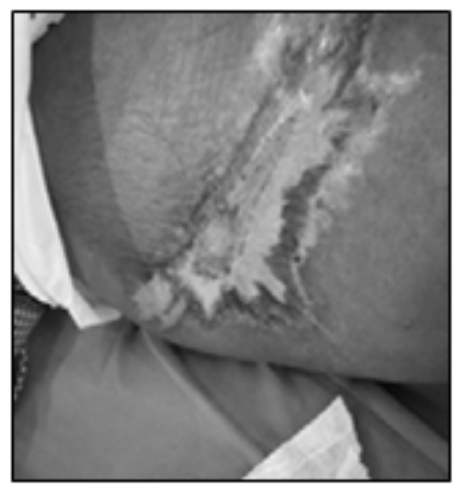

Fig 18. Wound right hip after 6 months

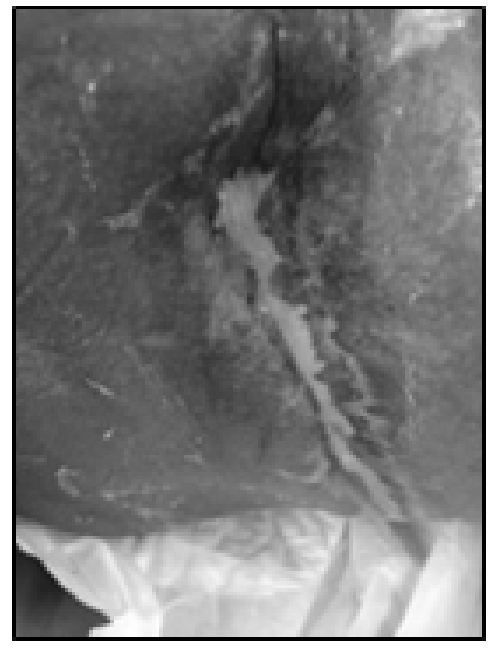

Fig 19. Wound left hip after 6 month 


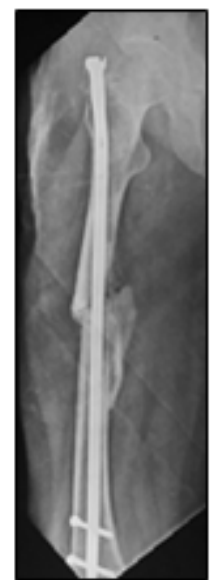

Fig 20. $\mathrm{X}$ ray right femur after 6 months

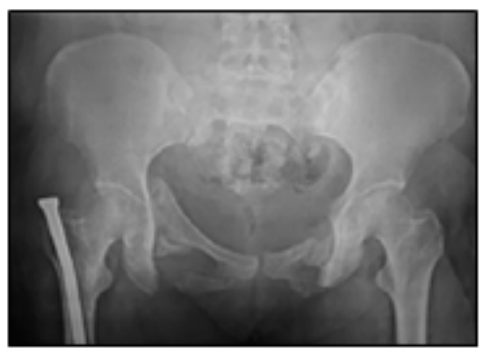

Fig 21. $\mathrm{X}$ ray $\mathrm{PBH}$ after 6 months

\section{Conclusion}

Morel-Lavallee lesions are post-traumatic closed degloving soft tissue injuries where the skin and subcutaneous tissues are separated from fascia superficial to underlying muscle plane. Shear injury disrupts perforating vessels and lymphatics, thus creating a potential space filled with serosanguinous fluid, blood, and necrotic fat.

Morel-Lavallee effusions may be associated with pelvic, acetabular fractures or may also occur with blunt trauma in the absence of fracture. Morel-Lavallee lesions are most commonly seen in the trochanteric region and proximal thigh. Clinically, Morel-Lavallee lesions usually present as an enlarging painful lesion within the anterolateral portion of affected thigh with soft tissue swelling and fluctuance. Other reported sites of involvement are the trunk, lumbar, prepatellar, and scapular regions.

Perifascial plane gets filled up with blood, lymph, and debris due to disrupted capillaries. An inflammatory reaction results in the formation of a peripheral capsule, which may account for the perpetuation and occasional slow growth of the lesion.

In an acute trauma, Morel-Lavallee lesions require surgical interventions so as to prevent infection. However, these effusions may be initially missed or may take some time to develop, which can make clinical diagnosis difficult. In longstanding cases, these lesions may subsequently enlarge and become painful, leading to misdiagnosis of soft tissue tumor.

\section{References}

1) Hak DJ, Olson SA, Matta JM. Diagnosis and management of closed internal degloving injuries associated with pelvic and acetabular fractures. The Journal of Trauma: Injury, Infection, and Critical Care. 1997;42(6):1046-1051. Available from: https://dx.doi.org/10.1097/ 00005373-199706000-00010.

2) Scaranelo AM, Davanço RA. Pseudo cyst formation after abdominal liposuction-extravasations of Morel-Lavallee on MR images. Br J Plast Surg. 2005;58(6):849-851.

3) Vanhegan IS, Dala-Ali B, Verhelst L, Mallucci P, Haddad FS. The MorelLavallée lesion as a rare differential diagnosis for recalcitrant bursitis of the knee: Case report and literature review. Case Reports in Orthopedics. 2012;2012:1-5. Available from: https://dx.doi.org/10.1155/2012/593193. doi:10.1155/2012/593193.

4) Mellado JM, del Palomar LP, Díaz L, Ramos A, Saurí A. Long-Standing Morel-Lavallée lesions of the trochanteric region and proximal thigh: MRI features in five patients. American Journal of Roentgenology. 2004;182(5):1289-1294. Available from: https://dx.doi.org/10.2214/ajr. 182.5.1821289.

5) Zecha PJ, Missotten FEM. Pseudocyst formation after abdominoplasty - extravasations of Morel-Lavallée. British Journal of Plastic Surgery. 1999;52(6):500-502. Available from: https://dx.doi.org/10.1054/bjps. 1999.3154. 